Article

\title{
Pathways to the 'Good Life': Co-Producing Prosperity Research in Informal Settlements in Tanzania
}

\author{
Saffron Woodcraft ${ }^{1, *}$, Emmanuel Osuteye ${ }^{2}$, Tim Ndezi $^{3}$ and Festo D. Makoba ${ }^{3}$ \\ ${ }^{1}$ Institute for Global Prosperity, University College London, London, W1T 7NF, UK; E-Mail: saffron.woodcraft@ucl.ac.uk \\ 2 Development Planning Unit, University College London, London, WC1H 9EZ, UK; E-Mail: e.osuteye@ucl.ac.uk \\ ${ }^{3}$ Centre for Community Initiatives, 31515 Dar es Salaam, Tanzania; E-Mail: ccitanzania@gmail.com \\ * Corresponding author
}

Submitted: 19 April 2020 | Accepted: 6 August 2020 | Published: 31 August 2020

\begin{abstract}
Residents of informal settlements in urban centres in Africa are known to suffer disproportionate burdens of environmental and socio-economic inequalities and are often excluded from macro-level visions and policies that seek to make cities safer and prosperous (Birkmann, 2007; da Silva \& Braulio, 2014; Dodman et al., 2013). This tension undermines the validity of orthodox, 'expert-led' visions, policies and measures of prosperity that are distant from the lived-experience of marginalised urban residents. Based on new empirical work with communities in three informal settlements in Dar es Salaam, Tanzania, this article argues that novel methodological and theoretical approaches to co-producing context-specific policy-relevant knowledge about pathways to prosperity (translated by the communities as maisha bora, 'the good life') creates inclusive spaces for both community participation in processes of urban knowledge production and critical social enquiry that can lead to grounded theory building. By co-producing both an agreed and relevant methodological approach for the study, and its subsequent documentation and analysis, this work contributes valuable empirical insights about the capacities and capabilities of local communities to shape and influence urban policy-making and in this way speaks to calls for a global urbanism (Ong, 2011; Robinson, 2016) that brings diverse voices and geographies to urban theory to better account for the diversity of urban experiences and processes found in twenty-first century cities.
\end{abstract}

\section{Keywords}

Africa; community innovation; Dar es Salaam; informal settlements; knowledge co-production; prosperity; socio-economic inequalities; Tanzania

\section{Issue}

This article is part of the issue "Cities of Inclusion - Spaces of Justice" edited by Anja Nygren (University of Helsinki, Finland) and Florencia Quesada (University of Helsinki, Finland).

(C) 2020 by the authors; licensee Cogitatio (Lisbon, Portugal). This article is licensed under a Creative Commons Attribution 4.0 International License (CC BY).

\section{Introduction}

The United Nations' 2030 Agenda for Sustainable Development, which launched the 17 global Sustainable Development Goals (SDGs) in 2015, opens with the statement: "This Agenda is a plan of action for people, planet and prosperity" (United Nations, 2015, p. 1). It seeks to eradicate poverty and hunger, reduce inequalities and create the conditions to "ensure that all human beings can enjoy prosperous and fulfilling lives and that eco- nomic, social and technological progress occurs in harmony with nature" (United Nations, 2015, p. 2).

This vision of human and non-human flourishing represents a significant shift from the definition of prosperity as material wealth, fuelled by economic growth, which dominated global policy throughout the 20th century (Moore \& Woodcraft, 2019). It signals potential for the emergence in urban policy and governance of a more expansive, equitable and inclusive understanding of prosperity, which acknowledges that the range of conditions, 
rights and freedoms, and capacities necessary for people everywhere to live a 'fulfilling life' extend far beyond sustainable economies, inclusive growth and decent work.

In this article, we argue that at the beginning of the 'decade of delivery' (2020-2030) on the SDGs, policyrelevant knowledge for transformative action on prosperity is lacking. Prosperity is under-studied and undertheorised relative to concepts like poverty, risk, resilience, quality of life and wellbeing in urban and social theory. Much of the knowledge currently driving policy and action on prosperity, in particular in the Global South, is based on concepts and measures developed by the World Bank to operationalise its mission goals of poverty reduction and shared prosperity. The Bank's mission agenda seeks to address the issue of income inequality in relation to inclusive growth (Basu, 2013), hence shared prosperity is narrowly conceptualised as "the growth in the income or consumption of the bottom $40 \%$ of the population in a country" (World Bank, 2016, p. 1). The Bank's approach has attracted widespread criticism for focusing narrowly on income inequality and failing to reflect the multi-dimensional nature of poverty, particularly at the subnational level (Alkire \& Santos, 2013; Shifa \& Leibbrandt, 2017) and without a distinction between rural and urban contexts (Khan, Lucci, \& Bhatkal, 2016; Satterthwaite \& Mitlin, 2014).

Academic literature on prosperity is also limited in scope (Woodcraft \& Moore, in press). The disciplinary dominance of economics and psychology in the burgeoning field of wellbeing and happiness studies drives a narrow conceptualisation of prosperity as 'wealth plus wellbeing' (Moore \& Woodcraft, 2019). Such approaches measure the levels of wellbeing generated by a nation's economic productivity, employment and household income (Diener, 1984; Diener \& Suh, 1997; Easterlin, 1974), adopting a universal definition of wellbeing as a state of individual happiness, life satisfaction, absence of anxiety and feeling that life is worthwhile (Tay \& Diener, 2011). In this context, cross-cultural studies addressing the measurement equivalence of wellbeing, happiness and life satisfaction in different contexts have proliferated (Delle Fave et al., 2016; Diener, Ng, Harter, \& Arora, 2010; Disabato, Goodman, Kashdan, Short, \& Jarden, 2016; Fadijia, Meiring, \& Wissing, 2019; Oyserman, Coon, \& Kemmelmeier, 2002), prompting a critique of efforts to translate 'global' measures to developing country contexts rather than paying attention to differences in the meaning, value and relevance of these concepts in the Global South (Camfield, 2012; Fadijia et al., 2019; Phillips \& Wong, 2016; White, 2009, 2015).

While participatory research examining poverty as a lived and multi-dimensional experience is wellestablished (Brock \& McGee, 2002; Robb, 1998), similar approaches to building context-specific multidimensional models of wellbeing and quality of life are less common (Camfield, 2012; Fadijia et al., 2019), and studies examining 'lay' meanings of prosperity in the Global South are notably absent from quality of life and wellbeing literature. As a consequence, prosperity is often presented in development literatures and policies in a binary relation to poverty: 'prosperity' being the outcome of poverty reduction efforts that focus on wealth, assets and enhanced livelihoods (Msambichaka, Mduma, Selejio, \& Mashindano, 2016; World Bank, 2016). This normative framing limits prosperity to material concerns, overlooking research acknowledging that categorising people as 'poor' or 'living in poverty' can misrepresent their lived experience, which is not always one of lack, deficit or deprivation in other domains of life (Sen, 1999). Research examining definitions of wealth and forms of assets ownership in rural Tanzania identifies the limitations of commonly used asset indices to meaningfully measure prosperity, noting a range of issues from collective rather than individual asset ownership and asset use rather than asset ownership, as obstacles to meaningful and accurate measurements (Brockington, Howland, Loiske, Mnzava, \& Noe, 2018; Howland, Noe, \& Brockington, 2019). This points to the importance of theorising, conceptualising and measuring prosperity as both a multi-dimensional and situated experience, which is shaped by cultural meanings and values, individual aspirations and systemic and structural factors.

The lives and futures of individuals and communities, in particular in cities in the Global South, will depend on the forms of evidence and knowledge that drive policy and action on the SDGs in the next decade. Delivering shared prosperity, re-imagined on the terms of Agenda 2030 as fulfilling and prosperous lives for people everywhere within planetary constraints, will be a highly complex and politicised process requiring new forms of dialogue within and between societies about whose visions of prosperity are put into action and the constraints and trade-offs to be negotiated. A critical question at this pivotal moment then is: In whose hands should this process of knowledge production lie?

We argue that transformative action for shared prosperity requires new, more democratic and accountable forms of knowledge that can bridge the gap between expert-led theories and concepts and diverse, culturally-specific meanings, values and prosperity practices. Measurement frameworks must be developed from knowledge and understanding about prosperity as a lived experience in ways that allow for action on the ground and meaningfully include marginalised communities in the design and delivery of policies, thereby making them co-produced and relevant (Durose, Beebeejaun, Rees, Richardson, \& Richardson, 2012). This is particularly relevant in urban centres in Africa, where the urban poor suffer disproportionate burdens of environmental and socio-economic inequalities and are often excluded from macro-level visions and policies that seek to make cities safer and prosperous (Birkmann, 2007; da Silva \& Braulio, 2014; Dodman et al., 2013).

In this article, we describe an innovative process of knowledge co-production with communities in three informal settlements in Dar es Salaam, which has gen- 
erated a new context-specific framework for conceptualising prosperity (maisha bora) based on lived experience. Community co-production methods are wellestablished in fields such as international development, humanitarian and resilience-building research and processes (Collodi, Di Vicenz, Murphy, \& Visman, 2017; Galuszka, 2019; Osuteye et al., 2019). However, having settlement dwellers lead a process of knowledge production for action on prosperity is unusual and opens up new directions for the methodological application of coproduction. Co-production is understood in this article as a deep engagement with different perspectives to create knowledge that can support the development and implementation of progressive policies and planning; resting on an epistemology of knowledge that challenges unitary visions and instead embraces knowledge production borne of the confrontation and juxtaposition of multiple ways of living, working and seeing the city (Osuteye et al., 2019). Co-production, therefore, marks a point of departure from conventional expert-led, top-down and centralised approaches, based on an appreciation of citizens' views, knowledges, experiences, preferences and needs, with communities then contributing to improved outcomes and achievable solutions to urban challenges (Galuszka, 2019; Ostrom, 1996). It is particularly relevant in the Global South as a means of overcoming institutional bureaucracies and regulatory norms that are exclusionary and otherwise counterproductive for the welfare of the urban poor or informal settlements (Galuszka, 2019; Watson, 2014). The relevance and utility of coproduced knowledge in urban processes goes beyond the provision of requisite services in contexts where communities were hitherto detached from development, to a more central recognition of the value of community knowledge in conceiving, shaping and actively contributing to the urban realities they aspire to. Co-production of visions of shared prosperity constitute a space of inclusion where marginalised urban communities have a central role in envisaging alternatives and more just urban futures.

\section{Context and Case Study Sites}

Dar es Salaam as the main commercial and cosmopolitan hub of Tanzania is one Africa's fastest growing urban centres, driven by an influx of residents from rural and suburban regions. It has an estimated population of over 5.5 million (up from 4 million in 2012 census) and an average growth rate of 5.8 percent. It is expected to expand by more than $85 \%$ through the next decade and exceed the 10 million mega-city status by mid-2030s (African Development Bank, 2014; Sturgis, 2015; see Figure 1).

Although urban growth in Dar es Salaam provides some economic opportunities for residents, the rapid population growth has outstretched the supply of adequate and affordable housing and other requisite services. As a result, about $70 \%$ of the population lives in informal or unplanned settlements (see Figures 2 and 3) leading to increasing socio-economic and spatial inequalities (Abebe, 2011; Kombe \& Kreibich, 2006; URT, 2000), and the rate of growth of the informal settlements is two times the average urban growth rate in the City (Kombe, Ndezi, \& Hofmann, 2015).

Widespread informality and unplanned settlements are a manifestation of poverty and social exclusion that occurs in many African cities, as they house the urban poor, recent migrants and other marginalised groups who are unable to afford improved land and rental housing in the city (UN-HABITAT, 2003). This is coupled with the growing demand for proximal housing in areas that support livelihood opportunities such as small-scale industries and markets near the central business districts, major transport nodes and harbour. Consequently, many residents live in overcrowded conditions in hazardous locations, such as floodplains, riverbanks and wastelands, which further expose them to risks such as flooding, disease outbreaks further accentuating poverty and inequalities (Abebe, 2011). Besides the obvious housing and environmental challenges that residents of informal settlements face, and the need to fill infrastructural deficits, there remains a more compelling imperative for planners and urban managers to understand the role of

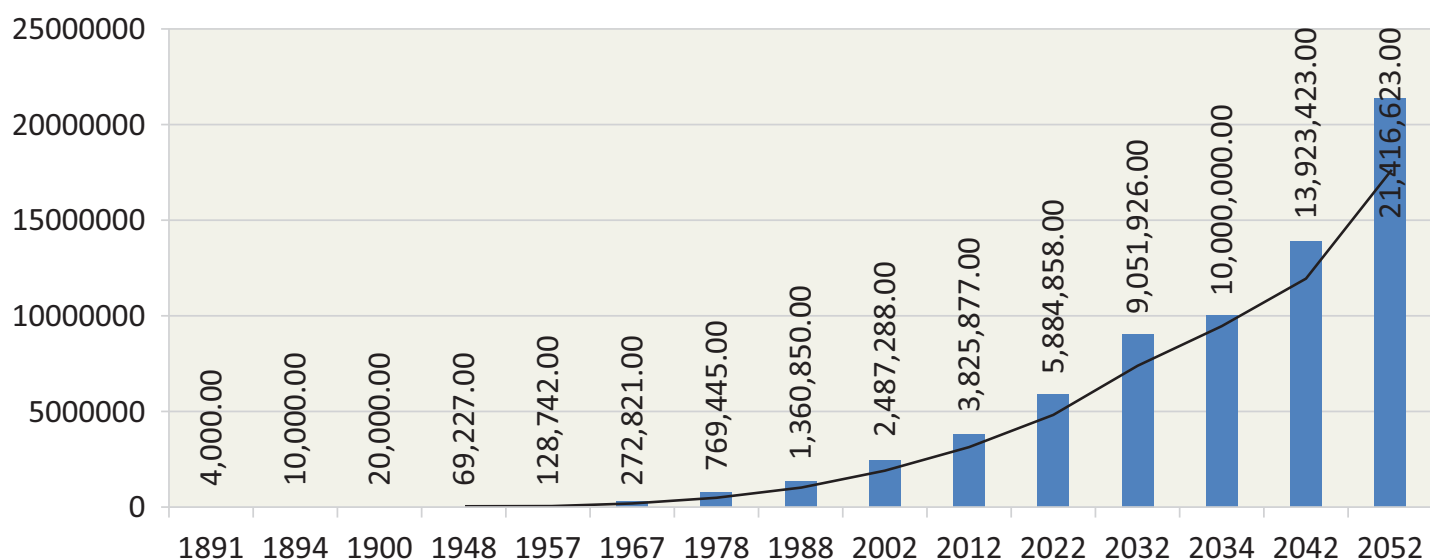

Figure 1. Population growth trend for Dar es Salaam city (1891-2052). Source: Sturgis (2015). 


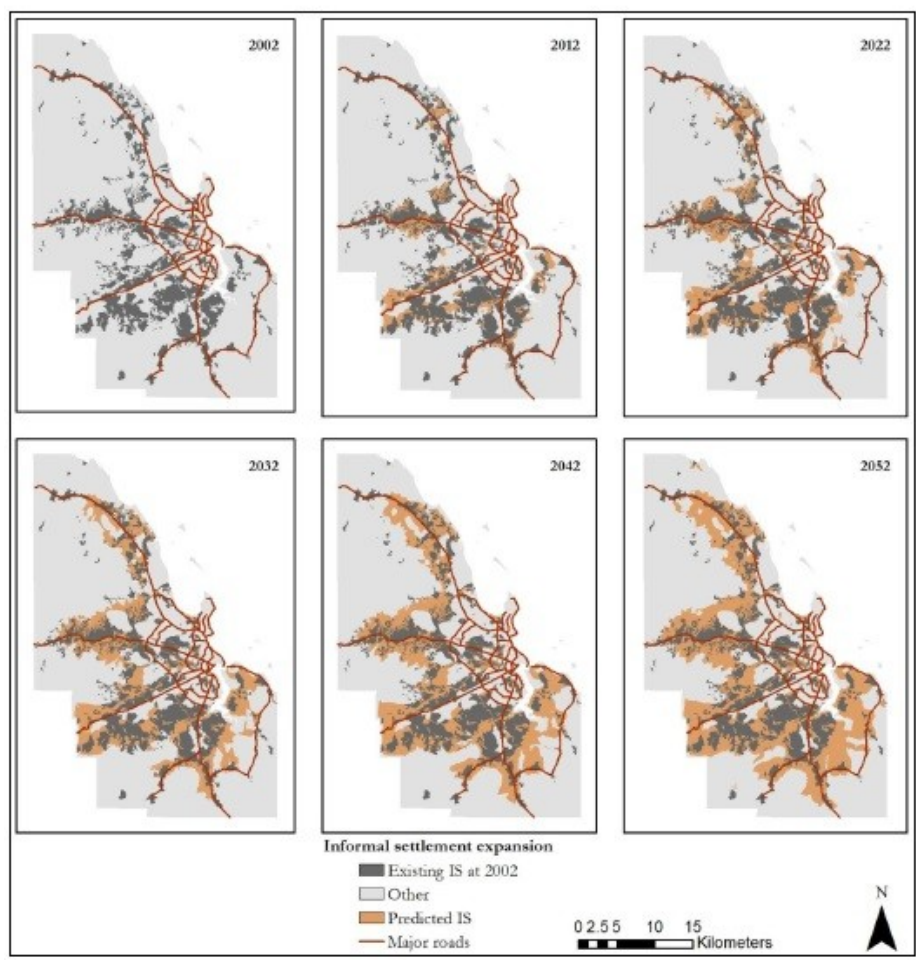

Figure 2. Projected informal settlement expansion in Dar es Salaam (2002-2052). Source: Abebe (2011).
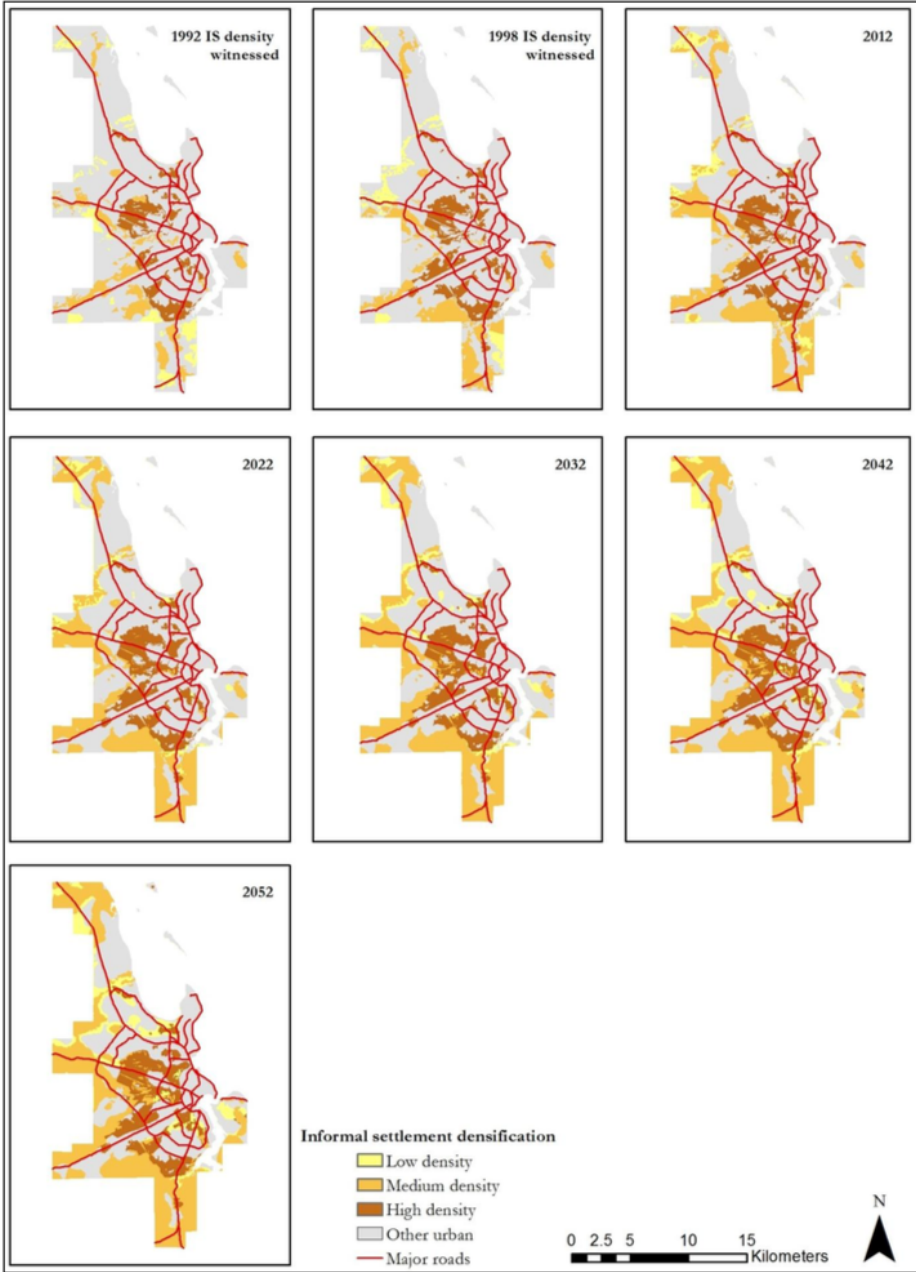

Figure 3. Projected densification of informal settlements in Dar es Salaam (1992-2052). Source: Abebe (2011). 
socio-economic factors and other forces that underpin organic urban growth (Kombe, 2005), including how the wellbeing and prosperity of residents can be understood and improved.

This study was conducted in three informal settlements in Dar es Salaam selected from three different Municipal areas: Mji Mpya, Bonde La Mpunga and Keko Machungwa. Administratively, the city is divided into five municipalities, which are subsequently divided into Wards, Sub-Wards (called 'Mtaa') and Ten Cell Units. The leadership of these devolved local government structures are appointed by the central government with the exception of the Sub-Ward leaders who are elected by residents. The size of Sub-Wards varies in area and population and may cover one or more informal settlements. For this study, each of the three settlements represent separate Mtaas, within their respective Wards and Municipalities. The selected Mtaas were further zoned for ease of access and navigation to ensure further spatial spread and representation in the sampling of respondents and methods employed (see Figure 4). The three selected informal settlements are representative of the nature and distribution of informality in Dar es Salaam which are typically described as either 'booming' or 'saturated,' mainly as a reflection of housing vulnerability and density (Abebe, 2011). The settlements are said to be booming when despite the formation of a critical mass of residents, they continue to attract new residents (including middle-income groups) and have less that $80 \%$ of land area used for construction. The saturated settlements on the other hand would have been formed ear- lier in the city's growth, and typically have more than $80 \%$ of land area used for construction. The saturated settlements have also been referred to as homogenous or uniformly unplanned and low-income settlements, as compared to the booming settlements that are mixed (Osuteye et al., 2020). Both Mji Mpya (Figure 5) and Keko Machungwa are saturated settlements closer to the central business district and major highways, and the third Bonde la Mpunga is typical of a booming settlement of mixed low income and middle-income housing clusters, built on reclaimed former rice fields in the periphery of the city.

The research was conducted in partnership with local NGO the Centre for Community Initiatives (CCI), which works with and supports the federated collectives of urban poor residents, under the Slum/Shack Dwellers International umbrella. $\mathrm{CCl}$, through its work on advocating pro-poor policy and practice in informal settlements in Dar es Salaam, has built strong relationships with many communities since its establishment in 2004 . The sampling of the settlements draws heavily on this existing relationship between the NGO, the federated groups and the local government leadership in all the three settlements.

\section{Prosperity Index Methodology: Understanding and Measuring Prosperity in Context}

This section describes the process of using the Prosperity Index (PI) methodology in Dar es Salaam, a process led by $\mathrm{CCl}$, working with a team of community researchers

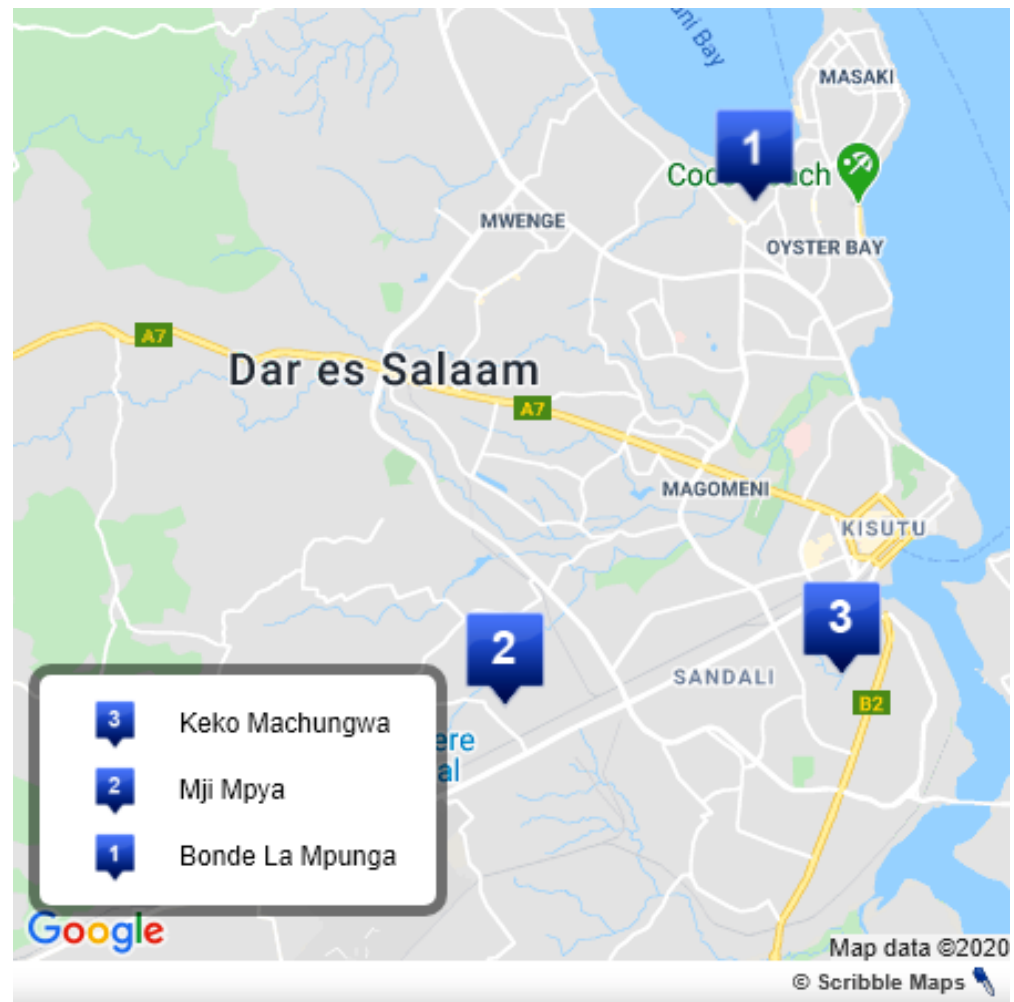

Figure 4. Map of Dar es Salaam, showing selected study sites. Source: Authors. 


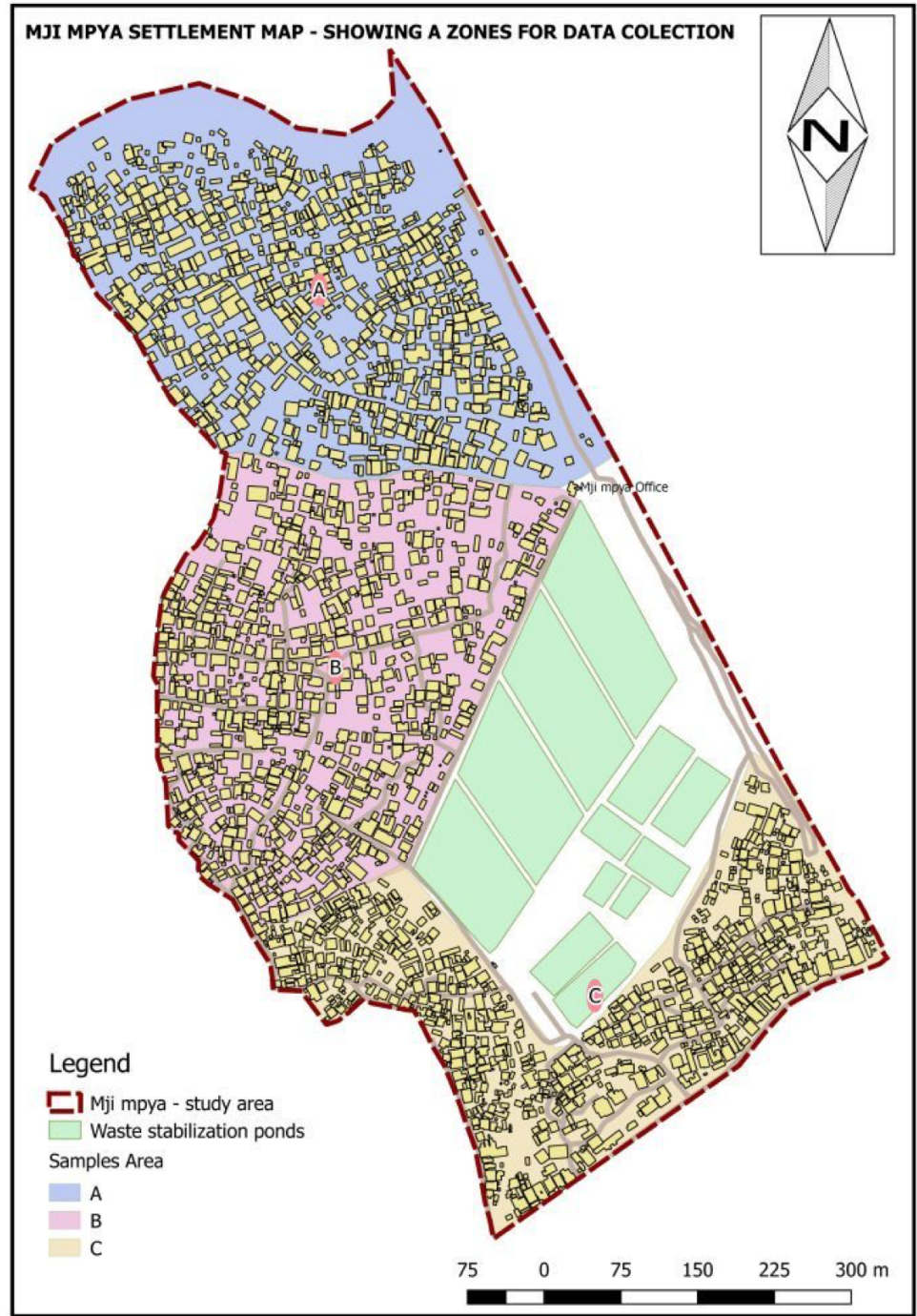

Figure 5. Map of the zonation of Mji Mpya sub-ward: one of three study sites. Based on the unpublished CCI and AXA Project output "Metrics for Policy Action in Urban Areas: Characterising Risks Facing Low-Income Groups" of 2018.

from three settlements and supported by academic researchers from the Institute for Global Prosperity (IGP) and the Development Planning Unit at University College London, as part of the "Knowledge in Action for Urban Equality" (KNOW) Project, funded by the Global Challenges Research Fund.

\subsection{Principles of the Prosperity Index Methodology}

The PI is a mixed-methods community co-production process, led by residents working in partnership with academic researchers and NGOs, to address the lack of context-specific policy-relevant knowledge about prosperity and to challenge normative definitions and frameworks that privilege income growth over a broader understanding of what people need to live fulfilling lives (Moore \& Woodcraft, 2019). The goal of the PI process is to co-produce a locally-and culturally-specific conceptual model of prosperity and prosperous lives, from which context-specific measures of prosperity can be de- veloped. And using new household survey data, local Prosperity Indices can be constructed.

Critically, the PI methodology recognises that knowledge innovation in itself is not sufficient to guarantee action or long-term changes in practice. In this regard, it recognises the limits of the actionable nature of coproduced knowledge, and equally the critical and distinct process of "knowledge integration" (Antonacopoulou, 2009), which must be situated within decision-making and governance frameworks. Consequently, the PI seeks to bridge this divide and offer insights to "understanding of the complex interrelationship between knowing what (cognitive/theoretical knowledge), knowing how (skills/technical knowledge), knowing to what end (moral choices) and doing (action/practice)" (Davoudi, 2015). While the process is citizen and community-led, a wider group of stakeholders are involved from the outset to build a coalition of actors with different capacities to respond to the knowledge that is generated (Woodcraft \& Anderson, 2019). 
The PI methodology is based on the following assumptions: (1) Co-producing knowledge about the lived experience of prosperity with citizens and communities-examining aspirations, practices, situated conditions and the effects of policy-generates more accurate, relevant and actionable knowledge about context-specific challenges and pathways to prosperity; (2) working collaboratively through multi-actor, multisector partnerships will create more transparent, democratic and inclusive spaces of knowledge production and critical social enquiry that can lead to grounded theory building; and (3) working through these multiple partnerships builds the capacity of communities and government, development and public actors, increasing the likelihood that new concepts, forms of evidence and ways of working are adopted. The PI methodology has been developed and tested by IGP, in partnership with citizen scientists and NGOs in cities in Lebanon, Nairobi and rural centres in Kenya, and five neighbourhoods in east London, UK.

The PI has been deliberately designed as a process for understanding prosperity as a lived reality in context rather than as a fixed research methodology. It is based on three principles that determine the essential purpose and nature of each step in the process yet leave considerable scope for local adaptation and context-specific action (see Table 1).

\subsection{Applying the Prosperity Index}

Methodology in Dar es Salaam The process began with a five-day capacity-building workshop (July 2019) to introduce the research team to the PI process. A series of participatory exercises and group discussions were used to guide the research team through a reflective process including: dialogues about the lived experiences of the group; personal aspirations for a prosperous life; societal and cultural expectations of prosperity; and a discussion about the factors that shape opportunities and capacities for settlement dwellers to live well.

The design process began with group discussions about the concept of 'prosperous and fulfilling lives'the terminology used in the SDGs - to identify an equivalent conceptual and linguistic translation, in this case to the Swahili maisha bora, 'the good life.' A series of collective exercises then followed-building on the PI core research questions to develop a discussion guide: design a programme of focus groups and one-to-one interviews with settlement dwellers; develop participatory exercises for use in the focus groups; and map actors from municipal and city government, public services, other NGOs, local businesses, development agencies and academic researchers to identify potential research participants and potential collaborators for longer-term action.

The research team co-designed a qualitative data collection programme to capture the lived realities of settlement dwellers and to enable people to describe maisha bora in their own terms and based on individual experiences. Consequently, focus group discussions and semi-structured interviews explored four broad questions: What does maisha bora mean to you? What are the most important things to live a good life in this community? Are there particular things here that allow people to live a good life or prevent it? What barriers are preventing you and your family from living a good life? It was important for the research team to examine both the meaning of maisha bora and the practical ways in which people negotiate between cultural expectations and individual aspirations of a good life and the multiple everyday and systemic factors that shape their opportunities.

Drawing on personal experiences of settlement life, the research team categorised different household types to identify a diversity of experiences such as levels of livelihood security and income, forms of vulnerability, visibility and capacities for community participation, and how these conditions are shaped by gender, age, ethnic-

Table 1. Prosperity Index principles.

Principle Description

1: Citizen and community-led partnerships for knowledge co-production and action

The process is co-initiated by residents working in partnership with NGOs and other local actors to co-produce knowledge for action on prosperity in ways that are inclusive, transparent and locally accountable.

2: Knowledge based on an in-depth understanding of the lived experience of communities

3: Action, policy and metrics built on local visions for prosperous and fulfilling lives
Underpinned by in-depth qualitative investigation of culturally-specific specific meanings, values and practices of prosperity, and the intersections between individual and cultural aspirations for a prosperous life, individual practices in pursuit of a prosperous life and material, economic and political conditions that shape opportunities and obstacles to prosper (Moore \& Woodcraft, 2019).

Co-produced knowledge places local experience and priorities at the centre of action-developing policies, programmes, interventions and metrics-recognising this may challenge normative concepts and definitions of prosperity. 
ity, disability, housing tenure and other socio-economic variables. There was extensive dialogue about the importance of capturing a wide range of perspectives, the hidden voices and experiences in the settlement, and the ethics of researching prosperity with individuals who, for the most part, are living in poverty and with exposure to various shocks and risks. This led to a nuanced consideration of different experiences and identities, and a process that generated an intersectional framework for the recruitment of research participants taking account of gender, age, disability, marital status, and housing tenure and income-generating activities as proxies for class differences.

Two pilot focus groups were convened to test the research questions before data collection began in one settlement. The project was then expanded to a further two informal settlements, involving the recruitment and training of additional research team members-a process that was managed by the initial community research team. Between July and October 2019, a series of semistructured interviews (10) and focus groups ( $N=179$ ) were undertaken by community research teams in all three informal settlements, and a further six interviews carried out with municipal government officers, city policymakers, public agencies and academics.
In November 2019, a second five-day workshop focusing on capacity-building to collectively analyse and interpret data from the qualitative research phase was held in Dar es Salaam. The first three days focused on introducing the research teams to an open-coding method, building a coding framework based on the words and phrases used by research participants, and collectively coding data. The final two days of the workshop were spent discussing and interpreting the findings, organising coded data into thematic clusters, and collectively developing a multi-dimensional conceptual model to represent the factors and conditions that constitute a good life for settlement dwellers (see Figure 6). The exercises and extensive dialogue ensured the concepts and terminology used to represent thematic findings accurately expressed lived experience. The research team then proposed different ways to symbolise connectedness, reflecting the relationships between different components of a good life, before collectively agreeing on a chain (mnyororo) as an appropriate visualisation of the maisha bora model.

The next step in the co-production process is for the research teams to share the qualitative research findings, initial interpretations and conceptual maisha bora model. A public meeting will be held in each settle-

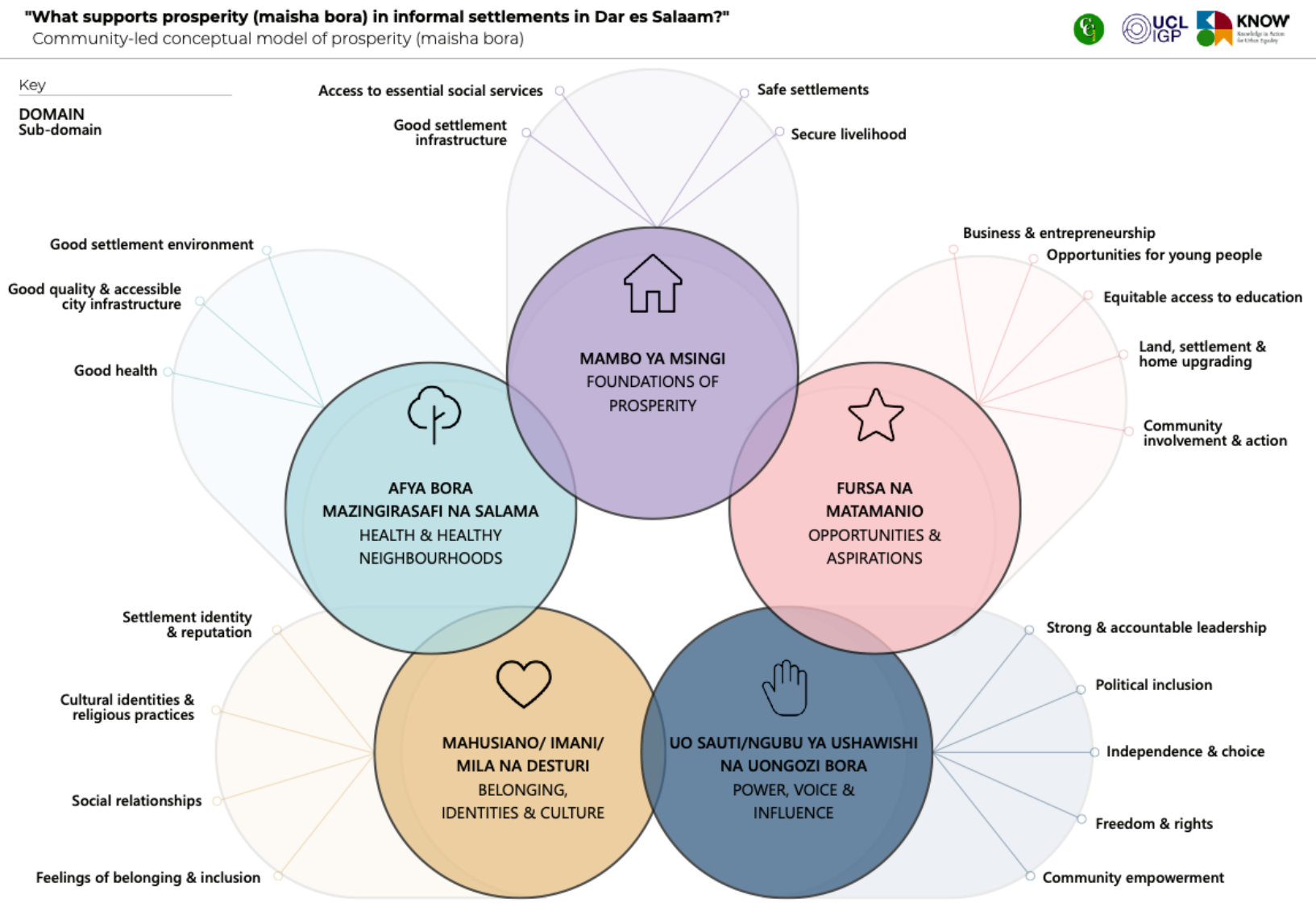

Figure 6. Maisha bora model Dar es Salaam. Based on the unpublished CCI and IGP KNOW Project output of 2019. 
ment for research participants, residents and community leaders to provide feedback on the conceptual model. Following public dialogues, the feedback will be analysed and any necessary refinements made to the conceptual model, before it is translated into a set of indicators to enable larger-scale quantitative analysis, comparing how opportunities to prosper vary in different settlements and by gender, housing tenure, economic circumstances and other variables. Household survey data will be collected in 2021 as the basis for developing a PI to track changes to prosperity in Dar es Salaam's informal settlements over the coming years.

\section{What Is Maisha Bora (the Good Life) for Informal Settlement Dwellers in Dar es Salaam?}

How does our understanding of prosperity and prosperous lives change when the starting point for inquiry shifts from 'experts' to the lived realities of communities? What does this kind of knowledge reveal about how policies and action to enhance prosperity should evolve? In this section we address these questions: First, we examine what maisha bora, a prosperous life, means from the perspectives of settlement dwellers. We look at the intersecting factors that residents say enable or obstruct pathways to prosperity and comment on peoples' accounts of inequalities within settlements, which create distinct, context-specific challenges, possibilities and experiences. Second, we reflect on what a lived experience lens can bring to our understanding of prosperity and the implications for policy.

\subsection{Prosperity as an Idea and Practice in Everyday Life}

Taking lived experience as the starting point, community researchers discussed the meanings and values that settlement dwellers associated with maisha bora, and the everyday challenges, practices and choices individuals make in pursuit of their own vision of prosperous and fulfilling lives.

The diversity of factors included in the maisha bora model (Figure 6) make it clear that in everyday life the conditions shaping prosperity encompass material, social, environmental, economic and political spheres and operate at different scales from individual to household to community, city and state. Figure 7 shows the 14 themes discussed most frequently across all three settlements in response to questions about the meaning of maisha bora and the most important things required to live a good life. Themes fall into two groups: seven priority themes that receive between 100 and 280 references in the research, and a further six themes that receive between 20 and 40 references. Discussing each theme in detail is outside the scope of this article. Instead, we sum-

What supports maisha bora, a good life, for residents in informal settlement in Dar es Salaam? Most common themes discussed in qualitative research by reference count

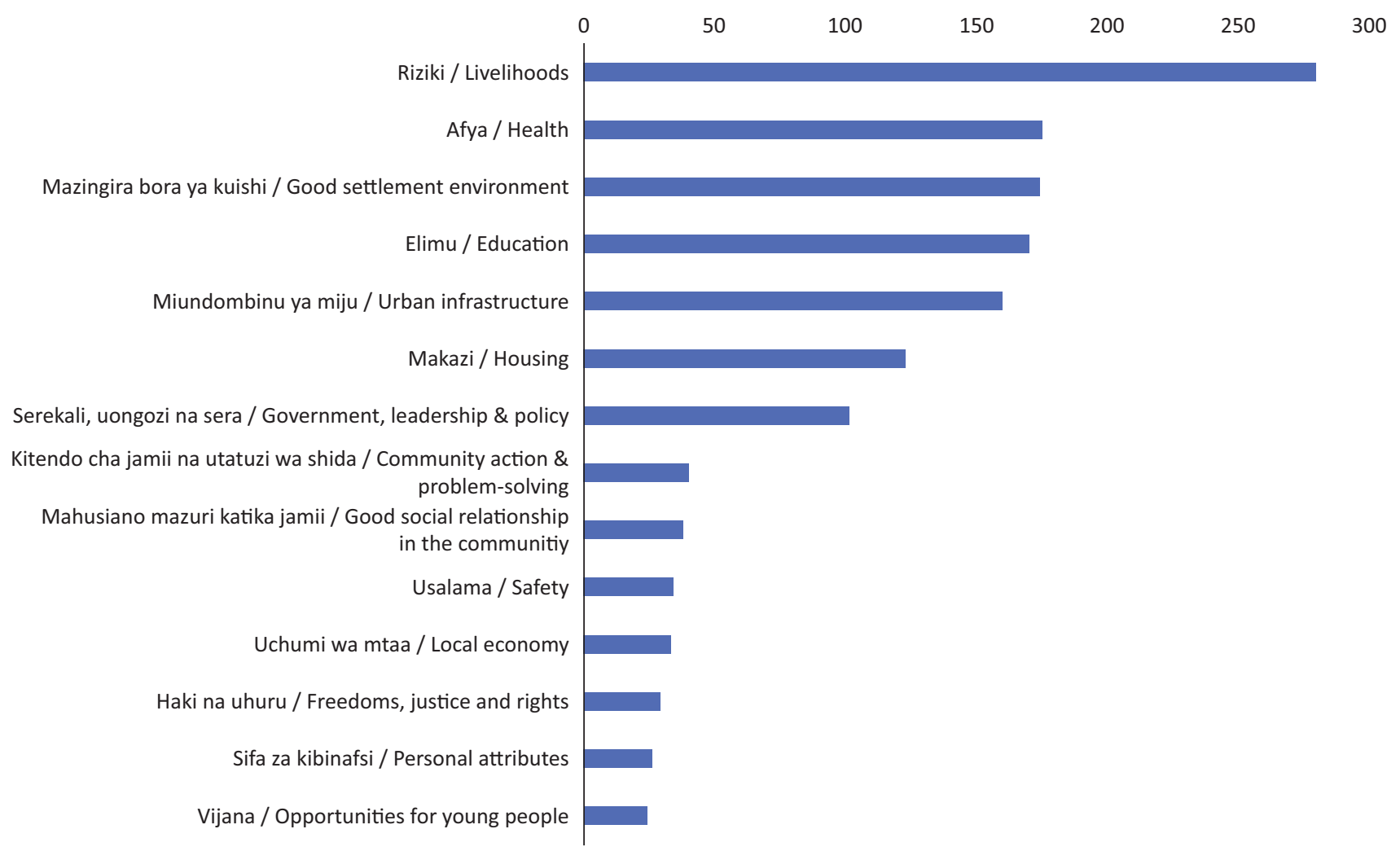

Figure 7. Most common themes in qualitative research in three informal settlements in Dar es Salaam (July-October 2019). Based on the unpublished CCI and IGP KNOW Project output of 2019. 
marise the seven priority themes and the significance settlement residents attached to these factors as determinants of a good life.

The first priority is secure livelihoods, which research participants described as reliable income-generating activity from employment or entrepreneurship that enables them to meet their basic needs (including adequate and affordable shelter, food and nutrition three times a day, safe water and affordable energy). Key social services (childcare, healthcare, education and transport) were identified as critical aspects of livelihood security, in terms of providing essential infrastructure and enabling conditions to generate income and care for household members. This highlights an important consideration in relation to policy on shared prosperity: Although academic literature recognises that individuals draw on a range of assets and capacities to make a living (including access to land, food production, social networks and services, in addition to income-generating activities; Chambers \& Conway, 1992), sustainable livelihoods are more narrowly defined in Tanzania's policy frameworks as income growth, poverty reduction and enterprise in relation to green growth (UNDP, n.d.). Settlement dwellers' accounts demonstrate the tightly interwoven nature of livelihood security and settlement conditions for example, reliable income-generating activity is essential in urban settlements to obtain nutritious food, rent or upgrade housing, and afford transport costs to access markets, work and essential services. Secure income enables some households to privately access clean water and energy.

Discussions about health and good settlement environments also focused on interactions between individual aspirations for good physical and mental health, individual circumstances such as hunger, chronic health conditions and wellbeing, and wider conditions in the settlement (clean air, safe water, lack of pests, proximity to polluting industries), and in the city more broadly that can support good health including both provision of hospitals, health centres, maternal and child health services, and capacities to access those services (health insurance, able to pay fees, transport connections and affordability to reach services, which were particularly challenging for elderly and disabled residents). Similarly, access to good quality and free childcare and basic education are described as important foundational conditions for a good life, in terms of personal development and attaining secure employment or income-generating activities. Educational provision is a common measure of human development and prosperity, however, participants identified the importance of other forms of education for youth and adults specifically relating to capacity-building for business and enterprise, and to enhance capacities to access micro-credit, loans and capital for investments, and household and business financial management to reduce problems associated with debt.

Housing and secure shelter are acknowledged as a basic need and foundational for a good life. However, discussions about aspirations for, and pathways toward, maisha bora recognise the multiple significances and possibilities afforded by secure land and housing rights, whether ownership or tenancy, in the present and future. Examples included control over housing upgrading and expansion, opportunities for small scale enterprise and industries that additional space allows, including food production and animal rearing which both offer scope to generate additional revenue.

Questions of individual agency, space for community action and enterprise, power and local leadership ran throughout the discussions, connecting themes around livelihood security and household living conditions to wider issues of community empowerment, enterprise and settlement improvement. This extract from a group discussion between Mji Mpya residents reflects a widely-shared sentiment that critical services like waste management should be "grasped by the community, not contractors":

We can be trusted by the municipality to form a group and facilities to remove solid wastes. It will create employment opportunities for unemployed people. [Put] in another way...we can solve community problems like waste management. (Woman, 45 years old, tenant and small business person, living in Mji Mpya for 20 years)

\subsection{Beyond the Poverty:Prosperity Binary}

It is evident, even from this brief discussion of research findings, that opportunities to prosper and live well are dependent on a wide range of conditions, networks, practices and infrastructures that extend beyond conventional poverty reduction measures such as increasing incomes and assets. Access to collective goods and services such as settlement sanitation and water, free childcare and healthcare are critical to living well: enhancing individuals' capacities for economic activity and reducing the risks of financial shocks related, for example, to illhealth. Policy based on a narrow formulation of shared prosperity as income growth for the poorest households obscures the complex inter-dependencies between individual capacities, settlement and wider city infrastructures, and economic and political conditions in enabling people to live prosperous and fulfilling lives. Examining prosperity through the lens of lived experience begins to illuminate how the conditions that shape maisha bora cut across social, economic, cultural and environmental domains and different scales of urban life and governance, as the following statements from research participants show:

City planning also contributes to people not having maisha bora, for instance the government was supposed to plan well this area before people started to establish settlements here, on the other hand, the government has constructed several drainage sys- 
tems at the middle of the settlement which contributes much to the transmission of diseases like malaria and cholera. (Woman in her 50s, home and small business owner, settlement resident for 30 years)

You cannot live in the area like this, which is an informal settlement with lack of improved sanitation service, poor drainage systems, often times flooded and lack of good road infrastructures, and say you have maisha bora even if you can manage to have three meals per day. Maisha bora depends [on the] type of settlement pattern. (Man in his 30s, settlement tenant for over 30 years, entrepreneur)

These examples illustrate how poor-quality city and settlement infrastructures undermine efforts to prosper and live well, regardless of the material resources households are able to deploy. The 'prosperity gains' that secure income, food, clean water and investments to upgrade family housing might offer are eroded by systemic factors, inequalities and risk exposures linked to urban governance, land use, industrial policy and political representation. Looking at questions of power and scale through their everyday effects on settlement life draws attention to the diversity of experiences within communities and the context-specific ways that social identities based on class, gender, disability compound forms of inequality and risk exposure. Woven through the research are issues of informality, marginalisation, and systematic exclusion from power and processes of decisionmaking that affect everyday life, highlighting the range and nature of inequalities experienced by marginalised communities and showing how urban processes produce context-specific obstacles to prosperous lives. Urban policies that construct prosperity and poverty in binary terms fail to take account of these critical intersections.

\section{Reflections on Co-Producing a Contextual Understanding of Prosperity}

This research shows prosperity to be multi-dimensional: Shaped by urban political economy, individuals' capacities to act, the daily practices and trade-offs that settlement dwellers in Dar es Salaam engage in to make a living and to live well. Examining maisha bora as a lived experience demonstrates the inadequacy of prosperity policies that focus solely on income growth and poverty reduction. Instead, what emerges from a 'lived prosperity' lens is a nuanced dialogue about the intersections and negotiations between meaning, practice, politics and structural factors. Neither knowledge co-production methods or intersectional analyses are new approaches in urban research and policymaking in the Global South (Castan-Broto \& Alves, 2018). However, attention to the situated meanings and practices of prosperity is a new field of inquiry that will require new models, research instruments and knowledges to shape policy and to ex- plore and theorise the relationships between prosperity and other policy concepts-wellbeing, resilience and poverty. We argue the unique value of the PI methodology is that it offers an opportunity for the integration of lived experience into urban policy, bringing alternate views about prosperity to evidence-based planning in contexts that rarely take account of non-dominant perspectives. Consequently, the novelty of the PI method used here is very much place-specific, and in the context of Dar es Salaam, both the in way the research is conducted and the critical involvement of local decisionmakers in the research design, data collection and shaping of interventions, marks a departure from the traditional participatory research, and the ways in which policy makers are used to being engaged.

Furthermore, the epistemological strength of the PI method lies in adding layers of subjective and experiential qualitative data to quantitative metrics, which allows policy and decision makers to gain valuable and measurable insights from communities. Its suitability is highlighted especially in settings like Dar es Salaam, where formal data may be unavailable, difficult to collect, inconsistent, or of poor quality. However it goes further than being just a useful process for objective data collection and is intended to stimulate local debate, priority setting, and action planning that altogether help to shape appropriate local interventions (Allen, Osuteye, Emmanuel, Koroma, \& Lambert, 2020; Twigg, Christie, Haworth, Osuteye, \& Skarlatidou, 2017). Besides the novelty of co-producing shared visions of prosperity, we also argue that the value and impact of the PI as a methodological process can be seen in four other ways, elaborated in the following sections.

\subsection{Co-Producing Pathways to Prosperity and Urban Equality}

Co-production is critical to create new forms of urban knowledge that reflect the diversity of contemporary cities and bring new voices, specifically from the Global South to policymaking. The PI goes beyond the knowledge-generation realm and proposes a framework for transformative change with the community at the centre. The co-produced PI emphasises the need for community-led action that can improve quality of life and livelihoods, whilst highlighting the broader questions about the functioning of power structures and how inequalities are reproduced (Castan-Broto \& Alves, 2018). It enables the generation of rich contextual understandings of the underlying issues and factors driving inequalities, that require such nuanced 'pathways' out of them. In this context, the PI as a co-produced approach and tool can be conceptualised as a 'pathway(s)' of shared prosperity that confronts the embedded structural and social inequalities in urban settings, such as the exclusion of community voice in planning, it is the application of such knowledge that marks the beginning of change that can be termed as transformative. 
The attempt to bridge the gap in inclusion draws on the relationship of the local NGO with the federation and community residents, which mediates the process of sampling and recruitment of respondents, based on a deeper understanding of where and how vulnerabilities manifest. Inclusion in this context has been conceptualised as a two-fold process of both recognition and participation of hitherto excluded voices and groups in envisioning, planning and implementing community aspirations beginning with the $\mathrm{PI}$. And in this regard the research design accounted for a collective discussion on the variety of experiences, demographics and social identities that were representative of the communities, and served as the basis for the purposive sampling (such as age, gender, disability, household composition, housing tenure, employment status, and income brackets). The PI's effort to address inclusion and diversity starts with an attempt to align with the different social identities that are recognised by the national government's legislative and policy structures on paper but nonetheless have in practice been excluded from decision making. This effort does not preclude the need to progressively work to recognise other forms of diversity and social identities in the frameworks used locally but consolidates the first steps that need to be taken now as a result of the identified gap.

Consequently, it is the recognition and utility of the $\mathrm{PI}$ as a community planning tool and not the outcomes alone that are noteworthy, as it contests and shifts the status quo of urban practitioners and policy makers in the Global South. It also sets the pace for innovative relationships between communities and decision-makers; using the PI as a tool to hold them to account and monitor their progress. The success of the latter remains subjective and open for testing, but the avenue for community groups (in the case of Dar es Salaam at the Mtaa level) to have co-produced such a tool, and ownership of the data, is worth celebrating.

\subsection{Capacity-Building for Urban Equality}

The process of developing the PI is embedded with opportunities and spaces for building capacities of community residents and leaders, the researchers' teams and participating local decision-makers geared towards advancing the ideals of urban equality. The PI levels the hitherto technical 'research fieldwork' process, and embraces the principles of knowledge co-production with partnerships of equivalence which re-balances internal power hierarchies and relationships within the teams, and the communities, purposively aiming to bring about contributions from participants that are innovative and propositional in seeking to challenge structural barriers to urban equality (Osuteye et al., 2019).

The involvement of local decision-makers in the research itself, makes a deliberate attempt to bridge the divide between research and practice. Officials in formalised urban planning systems are used to tools and metrics configured for the kinds of processes that they have to manage, and the PI allows communities to be able to 'speak their' languages through simplified outputs and metrics, and provide some basis and justification for claims made. The PI as a tool also allows for community knowledge generated to be captured and documented as a form of reference that allows for easier and continuous engagement. This is critical in urban settings like Dar es Salaam, that experience volatile political cycles and the high turnover of government and municipality staff.

\subsection{Creating Spaces of Justice and Inclusivity}

The inclusivity of the $\mathrm{PI}$ goes beyond the mere conceptual aggregation of diverse voices and actors to actively create moments and spaces for sustained engagement throughout the process. There is an explicit element of community mobilisation that exposes participants to new policy discourses such as those on 'shared prosperity.' Although the collective interaction of diverse actors and the community mobilisation during the coproduction is not the end goal, it creates invaluable spaces of inclusion. The PI creates the opportunity for diverse voices to get together through different 'spaces'shaping questions and methodology design, workshopping, community feedback mechanisms - and extending the spatial and geographic sites for interaction within the settlements. These spaces may be both intermediary and transient rather than a conceived output at the end of the process.

It is critical to note that the PI engages with, and conceptualises the 'spaces of inclusion' as factors of both time and space, and allows for the creation of 'intermediary' spaces of justice and inclusion through the process of co-production and action research. Consequently, the purposive long-term maintenance of the co-production process itself allows for the creation, curation and maintenance of the spaces of inclusion and justice.

Furthermore, the inherent capacity-building spaces in the process of $\mathrm{PI}$ earlier mentioned also become spaces of inclusion and contribute to the erosion of inequalities and, by extension, injustices that arise from those. The PI methodology recognises that building capacity is not merely consequential, but rather that it would not be possible for people to address structural inequalities without building their capacities, and breaking down dependencies and power hierarchies that reinforce inequalities at every level, beginning with the research design and co-production.

\section{Conclusion: Contributions to Theory and Practice}

The targeted focus of the co-produced PI, which allows for different forms of knowledges and experiences concerning what constitutes a good life for urban dwellers in Dar es Salaam to emerge, is a noteworthy contribution to research and policy-making spaces in urban Africa. 
This case contributes valuable empirical insights about the diversity of urban experiences found in twentyfirst century cities, and the capacities and capabilities of local communities to shape and influence urban policymaking. In this way the research speaks to calls for a global urbanism (Ong, 2011; Robinson, 2016) that brings diverse voices and geographies to urban theory. Its strength lies in its simplicity and replicability as an approach, bringing to light locally-specific dynamics that shape our understanding of prosperity in different contexts and offer new directions for theory-building and policy-making.

\section{Acknowledgments}

This article is part of the research project "Knowledge in Action for Urban Equality" (KNOW), funded by the ESRC under the Global Challenges Research Fund (GCRF). Project number: ES/P011225/1.

\section{Conflict of Interests}

The authors declare no conflict of interests.

\section{References}

Abebe, F. K. (2011). Modelling informal settlement growth in Dar es Salaam, Tanzania (Unpublished Master of Science dissertation). University of Twente, Netherlands.

African Development Bank. (2014). Tracking Africa's progress in figures. Belvéd: African Development Bank. Retrieved from https://www.afdb.org/sites/ default/files/2019/08/28/tracking_africas_progress_ in_figures.pdf

Alkire, S., \& Santos, M. E. (2013). A multidimensional approach: Poverty measurement \& beyond. Social Indicators Research, 112(2), 239-257. https://doi.org/ 10.1007/s11205-013-0257-3

Allen, A., Osuteye, E., Koroma, B., \& Lambert, R. (2020). Unlocking urban risk trajectories: Participatory approaches to uncover risk accumulation in Freetown's informal settlements. In M. Pelling (Ed.), Breaking cycles of risk accumulation in African cities (pp. 54-61). Nairobi: UN-Habitat.

Antonacopoulou, E. P. (2009). Impact and scholarship: Unlearning and practising to co-create actionable knowledge. Management Learning, 40(4), 421-430.

Basu, K. (2013). Shared prosperity and the mitigation of poverty: In practice and in precept (Policy Research Working Paper No. WPS6700). Washington, DC: The Worldbank. Retrieved from http://documents.worldbank.org/curated/en/ 223011468163444651/Shared-prosperity-and-themitigation-of-poverty-in-practice-and-in-precept

Birkmann, J. (2007). Risk and vulnerability indicators at different scales: Applicability, usefulness and policy implications. Environmental Hazards, 7(1), 20-31.
Brock, K., \& McGee, R. (2002). Knowing poverty: Critical reflections on participatory research and policy. Clerkenwell: Earthscan.

Brockington, D., Howland, O., Loiske, V.-M., Mnzava, M., \& Noe, C. (2018). Economic growth, rural assets and prosperity: Exploring the implications of a 20-year record of asset growth in Tanzania. The Journal of Modern African Studies, 56(2), 217-243. https://doi. org/10.1017/S0022278X18000186

Camfield, L. (2012). Quality of life in developing countries. In K. C. Land, A. C. Michalos, \& M. J. Sirgy (Eds.), Handbook of social indicators and quality of life research (pp. 399-432). Dordrecht: Springer Netherlands. https://doi.org/10.1007/978-94-007-2421-1_ 19

Castan-Broto, V., \& Alves, S. N. (2018). Intersectionality challenges for the co-production of urban services: Notes for a theoretical and methodological agenda. Environment and Urbanization, 30(2), 367-386.

Chambers, R., \& Conway, G. (1992). Sustainable rural livelihoods: Practical concepts for the 21st century (IDS Discussion Paper 296). Brighton: Institute for Development Studies. Retrieved from https:// www.ids.ac.uk/publications/sustainable-rurallivelihoods-practical-concepts-for-the-21st-century

Collodi, J., Di Vicenz, S., Murphy, R., \& Visman, E. (2017). Linking preparedness, response and resilience (LPRR). London: King's College and Christian AID.

da Silva, J., \& Braulio, M. (2014). City resilience index: City resilience framework. London: Ove Arup \& Partners International.

Davoudi, S. (2015). Planning as practice of knowing. Planning Theory, 14(3), 316-331.

Delle Fave, A., Brdar, I., Wissing, M. P., Araujo, U., Castro Solano, A., Freire, T., . . . Soosai-Nathan, L. (2016). Lay definitions of happiness across nations: The primacy of inner harmony and relational connectedness. Frontiers in Psychology. https://doi.org/ 10.3389/fpsyg.2016.00030

Diener, E. (1984). Subjective well-being. Psychological Bulletin, 95(3), 542-575. Retrieved from https://papers.ssrn.com/sol3/papers.cfm?abstract_ id $=2162125$

Diener, E., Ng, W., Harter, J., \& Arora, R. (2010). Wealth and happiness across the world: Material prosperity predicts life evaluation, whereas psychosocial prosperity predicts positive feeling. Journal of Personality and Social Psychology, 99(1), 52-61. https://doi.org/ 10.1037/a0018066

Diener, E., \& Suh, E. (1997). Measuring quality of life: Economic, social, and subjective indicators. Social Indicators Research, 40(1/2), 189-216. https://doi.org/ 10.1023/A:1006859511756

Disabato, D. J., Goodman, F. R., Kashdan, T. B., Short, J. L., \& Jarden, A. (2016). Different types of well-being? A cross-cultural examination of hedonic and eudaimonic well-being. Psychological Assessment, 28(5), 471-482. https://doi.apa.org/doi/ 


\subsection{7/pas0000209}

Dodman, D., Brown, D., Francis, K., Hardoy, J., Johnson, C., \& Satterthwaite, D. (2013). Understanding the nature and scale of urban risk in low-and middleincome countries and its implications for humanitarian preparedness, planning and response. London: IIED. Retrieved from https://pubs.iied.org/10624IIED

Durose, C., Beebeejaun, Y., Rees, J., Richardson, J., \& Richardson, L. (2012). Towards co-production in research with communities. Bristol: Connected Communities.

Easterlin, R. (1974). Does economic growth improve the human lot? Some empirical evidence. In P. A. David \& M. Warren Reder (Eds.), Nations and households in economic growth: Essays in honor of Moses Abramovitz (pp. 89-124). New York, NY: Academic Press.

Fadijia, A. W., Meiring, L., \& Wissing, M. P. (2019). Understanding well-being in the Ghanaian context: Linkages between lay conceptions of well-being and measures of hedonic and eudaimonic well-being. Applied Research in Quality of Life. https://doi.org/10.1007/ s11482-019-09777-2

Galuszka, J. (2019). What makes urban governance coproductive? Contradictions in the current debate on co-production. Planning Theory, 18(1), 143-160. https://journals.sagepub.com/doi/abs/10.1177/ 1473095218780535

Howland, O., Noe, C., \& Brockington, D. (2019). The multiple meanings of prosperity and poverty: A cross-site comparison from Tanzania. The Journal of Peasant Studies. https://doi.org/10.1080/03066150. 2019.1658080

Khan, A., Lucci, P., \& Bhatkal, T. (2016). Are we underestimating urban poverty? London: Overseas Development Institute. Retrieved from https://www.odi.org/publications/10358-arewe-underestimating-urban-poverty

Kombe, W. (2005). Land use dynamics in peri-urban areas and their implications on the urban growth and form: The case of Dar es Salaam, Tanzania. Habitat International, 29(1), 113-135. https://doi.org/ 10.1016/S0197-3975(03)00076-6

Kombe, W., \& Kreibich, V. (2006). Governance of informal urbanisation in Tanzania. Dar Es Salaam: Mkuki Na Nyota Publications.

Kombe, W., Ndezi, T., \& Hofmann, P. (2015). Translocal learning for water justice: Peri-urban pathways in India, Tanzania and Bolivia. London: The Bartlett Development Planning Unit.

Moore, H. L., \& Woodcraft, S. (2019). Understanding prosperity in East London: Local meanings and "sticky" measures of the good life. City \& Society, 31(2), 275-298. https://doi.org/10.1111/ciso.12208

Msambichaka, L. A., Mduma, J. K., Selejio, O., \& Mashindano, O. J. (Eds.). (2016). How can Tanzania move from poverty to prosperity? Dar es Salaam: Dar es Salaam University Press.
Ong, A. (2011). Introduction: Worlding cities, or the art of being global. Hoboken, NJ: Wiley Online Library. Retrieved from https://onlinelibrary.wiley.com/doi/ 10.1002/9781444346800.ch

Ostrom, E. (1996). Crossing the great divide: Synergy, and development. World Development, 24(6), 1073-1087.

Osuteye, E., Leck, H., Johnson, C., Ndezi, T., Makoba, F. D., \& Pelling, M. (2020). Communicating risk from the frontline: Projecting community voices into disaster risk management policies across scales. In M. Pelling (Ed.), Breaking cycles of risk accumulation in African cities (pp. 132-139). Nairobi: UN-Habitat.

Osuteye, E., Ortiz, C., Lipietz, B., Broto, V. C., Johnson, C., \& Kombe, W. (2019). Knowledge co-production for urban equality (Working Paper No. 1). London: University College London.

Oyserman, D., Coon, H. M., \& Kemmelmeier, M. (2002). Rethinking individualism and collectivism: Evaluation of theoretical assumptions and meta-analyses. Psychological Bulletin, 128(1), 3-72. https://doi.org/ 10.1037/0033-2909.128.1.3

Phillips, R., \& Wong, C. (2016). Handbook of community well-being research. Berlin: Springer.

Robb, C. (1998). Can the poor influence policy? Washington, DC: The World Bank. Retrieved from https:// doi.org/10.1596/0-8213-5000-5

Robinson, J. (2016). Comparative urbanism: New geographies and cultures of theorizing the urban. International Journal of Urban and Regional Research. Retrieved from https://onlinelibrary.wiley.com/doi/ full/10.1111/1468-2427.12273

Satterthwaite, D., \& Mitlin, D. (2014). Reducing urban poverty in the Global South. London: Routledge.

Sen, A. (1999). Development as freedom. Oxford: Oxford University Press.

Shifa, M., \& Leibbrandt, M. (2017). Profiling multidimensional poverty and inequality in Kenya and Zambia at sub-national levels (Working Paper No. 209). Cape Town: University of Cape Town. Retrieved from https://ideas.repec.org/p/ldr/wpaper/209.html

Sturgis, S. (2015, February 25). The bright future of Dar es Salaam, an unlikely African megacity. Bloomberg. Retrived from https://www.bloomberg.com/news/ articles/2015-02-25/tanzania-s-dar-es-salaamis-on-track-to-become-one-of-africa-s-mostimportant-megacities

Tay, L., \& Diener, E. (2011). Needs and subjective wellbeing around the world. Journal of Personality and Social Psychology, 101(2), 354-365.

Twigg, J., Christie, N., Haworth, J., Osuteye, E., \& Skarlatidou, A. (2017). Improved methods for fire risk assessment in low-income and informal settlements. International Journal of Environmental Research and Public Health, 14(2). https://doi.org/ 10.3390/ijerph14020139

UN-HABITAT. (2003). The challenge of slums. Nairobi: UN-Habitat and Earthscan Publication Ltd. 
United Nations. (2015). Transforming our world: The 2030 agenda for sustainable development (Report No. A/RES/70/1). New York, NY: United Nations. Retrieved from https://www.un.org/ga/search/view_ doc.asp?symbol=A/RES/70/1\&Lang=E

URT. (2000). National human settlements development policy. Dar es Salaam: Government Printer Dar es Salaam.

Watson, V. (2014). Co-production and collaboration in planning: The difference. Planning Theory \& Practice, 15(1), 62-76. https://doi.org/10.1080/ 14649357.2013.866266

White, S. C. (2009). Bringing wellbeing into development practice. Bath: University of Bath. Retrieved from https://researchportal.bath.ac.uk/en/publications/ bringing-wellbeing-into-development-practice

White, S. C. (2015). Relational wellbeing: A theoretical and operational approach (Working Paper No. 43). Bath: University of Bath.

Woodcraft, S., \& Anderson, B. (2019). Rethinking prosperity for London: When citizens lead transformation. London: Institute for Global Prosperity UCL.

Woodcraft, S., \& Moore, H. L. (in press). Problematizing 'urban prosperity': Is it 'in,' 'of,' or 'for' the city? London: IGP.

World Bank. (2016). Poverty and shared prosperity 2016: Taking on inequality. Washington, DC: World Bank.

\section{About the Authors}

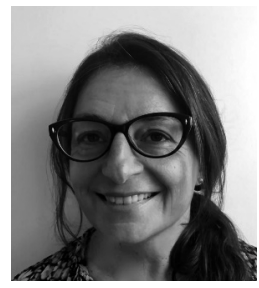

Saffron Woodcraft is a Principal Research Fellow at the Institute for Global Prosperity, University College London (UCL). Her research focusses on understanding lived experiences of prosperity and inequality and working with citizen social scientists, community organisations, policymakers and business to bring local understandings of prosperity into planning and decision-making processes that affect place-based strategies. Saffron is engaged in research in Tanzania, Cuba and the UK.

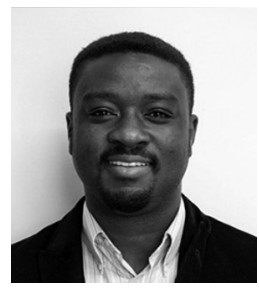

Emmanuel Osuteye is a Research Fellow at the Bartlett Development Planning Unit, University College London (UCL). His research interests are focussed on studying the governance, policy and institutional aspects of risk and disaster management in low-income urban centres, the interplay of formal and informal governance and planning structures on urban development in Africa, and participatory processes for community capacity building, poverty reduction and gender mainstreaming in sustainable development policy and practice in Africa.

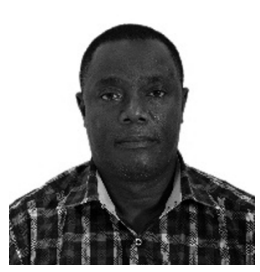

Tim Ndezi (PhD) is founding Director of the Centre for Community Initiatives (CCI) Organisation based in Tanzania. He holds a PhD from Loughborough University on water and sanitation management and has vast experience in integrating practice and research work in addressing urban challenges on water, sanitation, affordable housing and climate change. His research focus has been on urban poverty; urban risk and resilience; urban water and sanitation; and integration of nature-based olutions. In all this research, mainstreaming of gender and co-production has been a core in ensuring all actors are involved in the whole process to achieve sustainability.

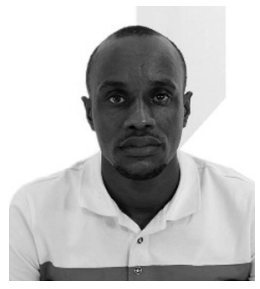

Festo D. Makoba is a Water and Sanitation Engineer at the Centre for Community Initiatives (CCl). With expertise in urban and rural water supply and treatment, low-cost sanitation, and geographical information systems (GIS). Working at CCI, Festo has been involved in undertaking various applied and action research with universities and institutions locally and internationally such as ARU, IIED, and UCL/DPU in low-income communities in Dar es Salaam. 